\title{
TEM observation of precipitates and their role to mechanical properties in Ti-5553 alloy heated to some temperatures up to $923 \mathrm{~K}$
}

\author{
E. Sukedai ${ }^{\left.1),{ }^{*}, \text { E. Aeby-Gautier }{ }^{2}\right), \text { M. Dehmas }}{ }^{3)}$ \\ 1) Okayama Univ. of Science; Okayama 700-008, Japan \\ 2) Institut Jean Lamour, UMR 7198 CNRS - Université de Lorraine, Nancy, France \\ 3) CIRIMAT, Université de Toulouse, CNRS, Toulouse, France. \\ *keikofs@mx31.tiki.ne.jp
}

\begin{abstract}
$\underline{\text { Abstract }}$
A Ti-5553 specimen was continuously heated to $923 \mathrm{~K}$ and simultaneously in-situ HEXRD profiles were taken. In addition, specimens heated at the same rate to several temperatures up to $923 \mathrm{~K}$ and further quenched were observed by transmission electron microscopy. Based on both results obtained, transformation sequence was clarified, precipitations of $\omega-, \alpha{ }^{\prime}$ iso $^{-}$and $\alpha$-phases were confirmed, and size and density of these precipitates were measured. Hardness values of those specimens were also measured. The hardening mechanism was considered as shearing-mechanism for specimens aged at lower temperatures and by-pass one for specimens aged at higher temperature. An attempt of distinction between $\alpha^{\prime \prime}$ iso - and $\alpha$ precipitates was also tried. Both precipitates were in needle-like shape and a possibility was suggested by measuring angles between two needle-shape precipitates on $\{110\}$ of the matrix and comparing with each other.
\end{abstract}

\section{Introduction}

Various thermo-mechanical treatments were developed for many practical $\beta$-Ti alloys to improve their mechanical properties [1-3]. One of the most important points for the improvement is controlling the nucleation and the growth of the product phases to form for example a high density of fine precipitates in the matrix [3]. Indeed, fine $\alpha$-particles obtained during aging treatments of specimen in a $\beta$-metastable state cause excellent advantages such as high strength and ductility to practical $\beta$-Ti alloys. Therefore, it is the fundamentally important knowledge to clarify and understand precipitation behavior of $\alpha$-precipitates due to aging and heating.

Precipitation behavior in Ti-5553 or Ti55531 alloy during aging treatment has been investigated using insitu XRD (HEXRD) with the high-energy beam-line at ESRF (Grenoble) [4, 5]. Depending on the heating rate, the precipitation of different phases as rising temperature to $923 \mathrm{~K}$ has been reported $[4,5]$, as well as the phase-transformation sequences. Indeed, when heating at $0.1 \mathrm{~K} / \mathrm{s}$, the following sequence is mentioned in [4]: $\alpha \rightarrow \beta+\omega \rightarrow \beta+\omega+\alpha " \rightarrow \beta+\alpha "+\alpha \rightarrow \beta+\alpha$-phase. The same sequence was characterized for other $\beta$-Ti alloys using the same method or conventional XRD [6-8]. In order to differentiate the base centered orthorhombic structure formed during aging from the martensitic structure formed during cooling, we will call it $\alpha$ " iso.

Precipitation during aging was also studied by TEM. Numerous authors report the precipitation of $\omega$ phase (hexagonal) at the lower temperatures [9]. This precipitation is followed by the precipitation of $\alpha$ phase $[8,10-12]$. No precipitation of an orthorhombic phase was generally mentioned. More recently, formation of an ordered faced centered orthorhombic structure, called O" was reported in Ti-5553 alloy in addition to the precipitation of $\omega$ and $\alpha$ phase at temperatures of about $598 \mathrm{~K}$ [13].

In the present study, the details of precipitates appeared in specimens of Ti-5553 alloy during the heating up to several temperatures, were investigated using the transmission electron microscopy (TEM). The hardness values of specimens heated to several temperatures were measured for evaluating hardening behavior. The hardness-variation due to heating to each temperature is discussed based on the results of HEXRD and TEM, and the hardening mechanism is also discussed based on the present result.

It is also discussed to distinguish $\alpha$ and $\alpha$ " iso -phase by utilizing the both results obtained by HEXRD and TEM observation.

(C) The Authors, published by EDP Sciences. This is an open access article distributed under the terms of the Creative Commons Attribution License 4.0 (http://creativecommons.org/licenses/by/4.0/). 


\section{Experimental procedure}

Chemical composition of Ti-5553 alloy was 4.9 Al, 5.1 Mo, 5.2 V, 2.7 Cr, 1500 ppm 0 and Ti-bal. in mass\%, and its $\beta$-transus temperature $1120 \mathrm{~K}$. Solution-treatment was carried out at $1163 \mathrm{~K}$ for $1.8 \mathrm{ks}$ in vacuum, followed by quenching into iced-water. Specimens were heated to 473, 623, 693, 773 and $923 \mathrm{~K}$ by heatingrate of $0.1 \mathrm{~K} / \mathrm{s}$ in vacuum, followed by quenching into iced-water. Micro-Vickers hardness values of each specimen were measured under the conditions with $4.9 \mathrm{~N}$ for $30 \mathrm{sec}$. Thin-foils specimens for TEM observation were prepared by electro-polishing method. Details of the conditions have been reported [14]. TEM observation was carried out using JEM 4000EX operated at $400 \mathrm{kV}$, Philips CM 200 operated at 200 $\mathrm{kV}$ and JEM-2100 Plus operated at $200 \mathrm{kV}$.

\section{$\underline{\text { Results and discussion }}$}

In Figure 1 are reported the in-situ HEXRD profiles obtained during heating up to the selected temperatures corresponding to the further TEM observation. At room temperature, only $\beta$ phase peaks are clearly present. As temperature rises, additional peaks appear on the diffraction diagrams. At $693 \mathrm{~K}$, peaks of $\omega$-phase (hexagonal structure) can be identified. However, modifications in the background can be noted for $2 \theta$ values ranging from 6.4 to $6.8^{\circ}$.

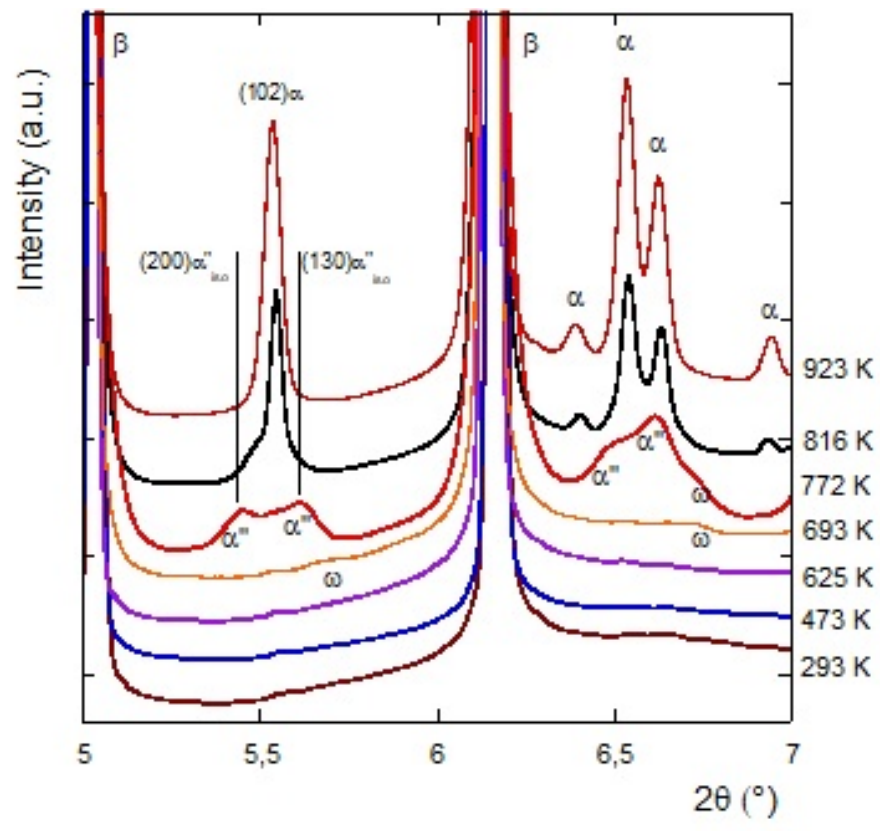

Figure 1: HEXRD profiles obtained at several temperatures during the heating.

At $772 \mathrm{~K}$, in addition to $\omega$-phase and $\beta$-phase, peaks of an orthorhombic phase appeared; they were considered as the peaks of the base centered orthorhombic structure, $\alpha$ " iso -phase [4]. As temperature increases, the intensity and position of $\alpha$ " iso -phase peaks vary, while the $\omega$-phase peaks disappear. This is visible for $2 \theta$ values ranging from 5.2 to $5.8^{\circ}$, for $(200) \alpha{ }^{\prime}$ iso and (130) $\alpha^{\prime \prime}$ iso peaks. The two peaks are distinctly observed at $772 \mathrm{~K}$. At $816 \mathrm{~K}$, one observes a peak and a shoulder and finally at $923 \mathrm{~K}$, a single peak corresponding to $(102) \alpha$.

The transformation-sequence of this alloy by heating at $0.1 \mathrm{~K} / \mathrm{s}$ is: $\beta \rightarrow \beta+\omega \rightarrow \beta+\omega+\alpha$ " ${ }_{\text {iso }} \rightarrow \beta+\alpha{ }^{\text {" }}$ iso $+\alpha \rightarrow$ $\beta+\alpha-$ phase as reported in [4].

Figure 2 shows electron diffraction patterns of specimens solution-treated quenched and re-heated to each temperature. The incident beams were parallel to $<110\rangle$ of the matrix. In Fig. 2(a), strong spots of the matrix and extra-diffuse intensities are visible. It seems that these diffuse intensities result from athermal $\omega$ phase. In Fig. 2(b), strong spots and diffuse intensities are also visible. In Fig. 2(c), diffuse intensities change to spotty ones. These spots result from $\omega$-phase and $\alpha{ }^{\text {iso }}$ (or $\alpha$ )-phase. It is difficult to distinguish $\alpha$ - and

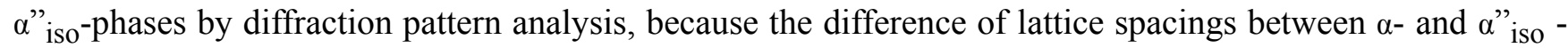


phase is within the limits of measurement errors $(3 \%)$. A discussion about their distinction will be mentioned later.
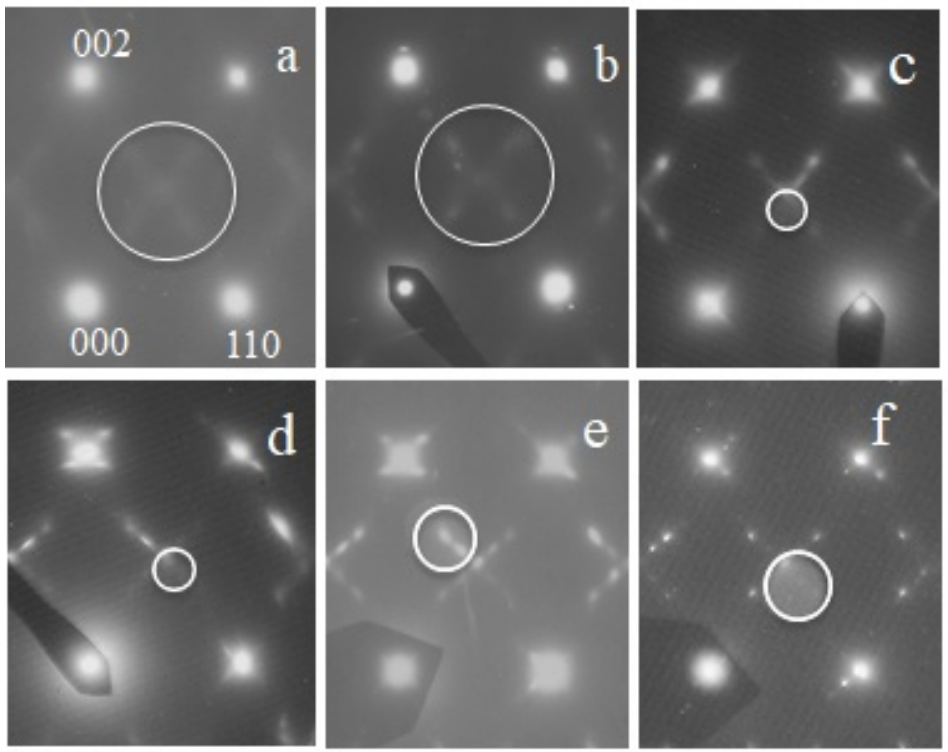

Figure 2: Electron diffraction patterns of specimens as-ST in (a) and heated to $473 \mathrm{~K}$ in (b), $623 \mathrm{~K}$ in (c), $693 \mathrm{~K}$ in (d), $773 \mathrm{~K}$ in (e) and $923 \mathrm{~K}$ in (f). Incident beams were parallel to $<110>$ of the matrix. White-circles indicate diffracted intensities and spots to take dark-field images in Fig. 4.

In Fig. 2(d) and (e), the similar diffraction spots are visible, but they become clearer than that in Fig. 2(c). In Fig. 2(f), clear spots appear near the positions of $\omega$-phase spots, which is named as $\omega$ '-spots. $\omega$ '-spots are also visible in Fig. 2(e). The $\omega$ '-spots have been reported in several $\beta$-Ti alloys after a long-time aging [15], and the crystal structure has been investigated. But precise structure of this phase is not clarified [14]. In addition, white-circles in Fig. 2 indicate diffracted intensities for taking dark field images shown in Fig. 4.

Figure 3 shows the same diffraction pattern as Fig. 2 (c), which is used to indicate identifications of each spot. Spots indicated by white-arrows with $\omega, \alpha$ "iso- 1 and $\alpha$ "iso- 2 are diffracted spots from $\omega$ and $\alpha$-phases, respectively. Indexes $\alpha$ "iso-1 and $\alpha$ "iso-2 are 10-10 and -1100 respectively, and they are variants of $\alpha$ " iso phase. Other spots are double diffracted ones from $\omega$ - and $\alpha{ }^{\text {iso }}$-phases. 


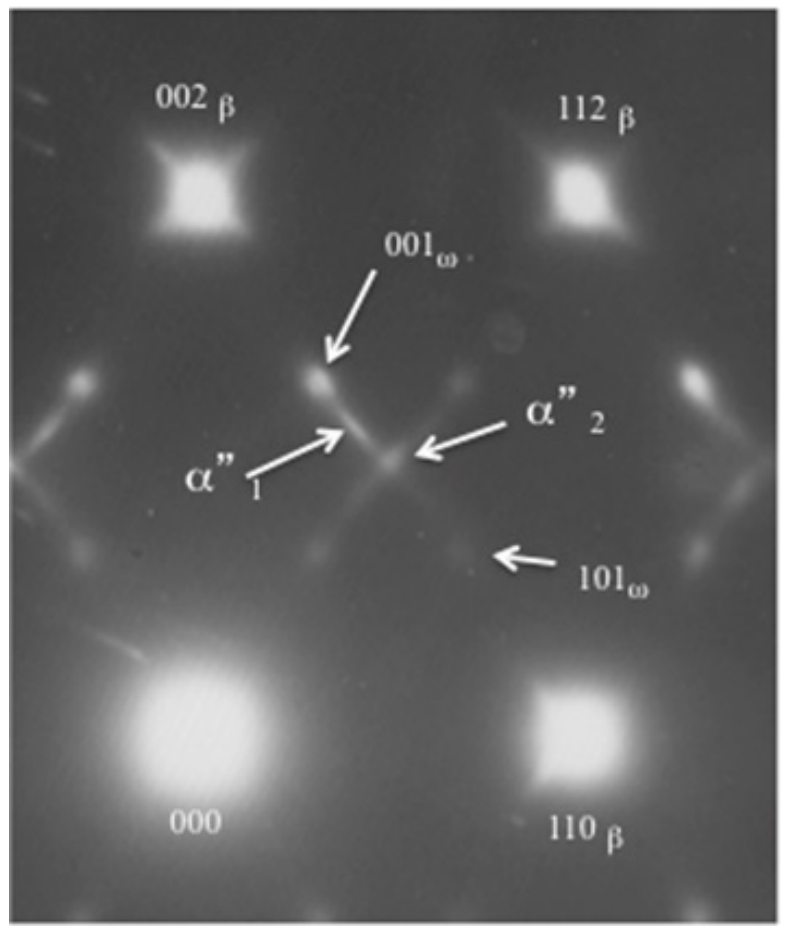

Figure 3: Electron diffraction pattern of a specimen heated to $623 \mathrm{~K}$ in a quadrant. White-arrows indicate $\omega$, $\alpha{ }_{1}$ and $\alpha{ }_{2}$ spots. Indexes of $\alpha{ }_{1}$ and $\alpha{ }_{2}$ spots are indicated in the text. Other fine spots are double diffraction spots.

Figure 4 shows dark field images. Figure 4(a) was taken using diffuse intensities inside of the white-circle in Fig. 2(a), and it shows that there are many small bright images. These precipitates might be athermal $\omega$ phase. Figure 4(b), taken using diffuse intensities inside of a white-circle in Fig. 2(b), reveals that the morphology of bright images changes to spotty. Figure 4(c) was taken using a spot indicated by a whitecircle in Fig. 2(c); and many fine particles are visible. These fine needle-like particles are $\alpha$ " iso (or $\alpha$ )precipitates. It is found that the size of these fine needle-like precipitates is larger than particles in Fig. 4(b). Figure 4(d) was taken using a spot indicated by a white-circle in Fig. 2(d). Needle-like precipitates can be seen along to two directions. The length of these needle-like precipitates is larger than that of the images in Fig. 4(c).
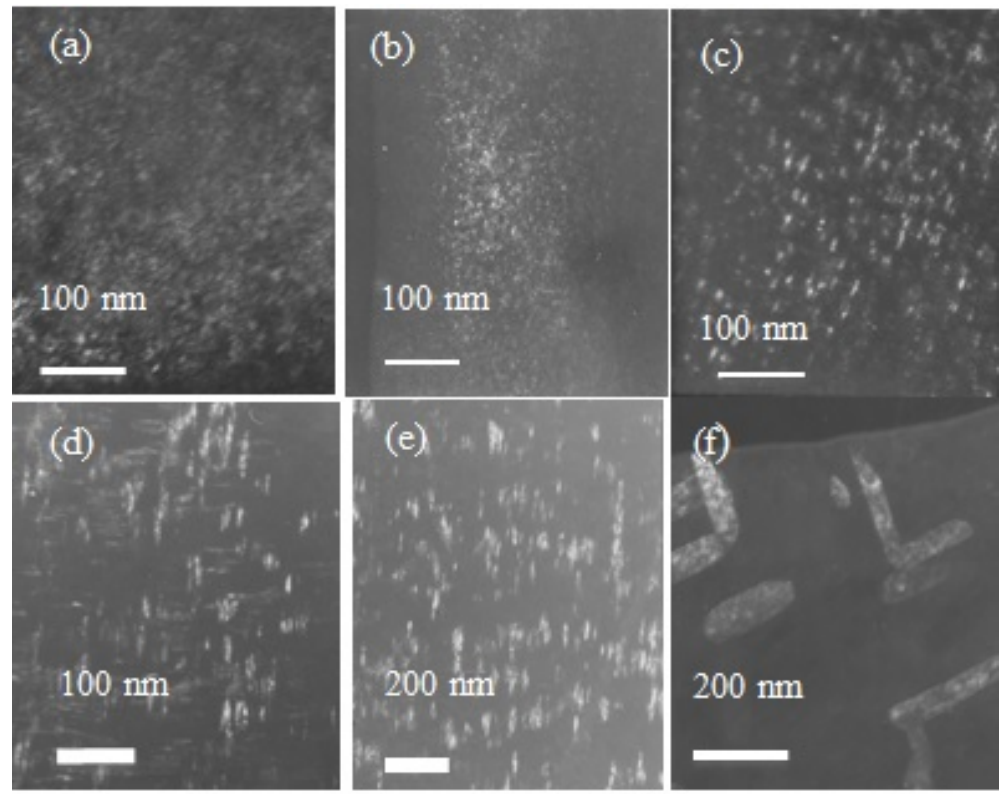

Figure 4: Dark field images of specimens heated at each temperature: (a) As-ST, (b) $473 \mathrm{~K}$, (c) $623 \mathrm{~K}$, (d) $693 \mathrm{~K}$, (e) $773 \mathrm{~K}$, (f) $923 \mathrm{~K}$. 
These precipitates are predicted as $\alpha$ "iso-ones, because the sequence of phase appearance in this alloy heated at this heating condition is reported [4]. Figure 4(e) was taken using a spot indicated by a white-circle in Fig. 2(e). Needle-like precipitates are larger and clearer than those of Fig. 4(d). These precipitates are considered as $\alpha$ "iso -precipitates due to a HEXRD profile at $772 \mathrm{~K}$ in Fig. 1. Figure 4(f) was taken using diffraction spots inside a white-circle in Fig. 2(f), and it is found that significant clear precipitates grew due to heating to 923 K. Due to a HEXRD profile of Fig. 1, these precipitates are considered as $\alpha$-precipitates. The size of precipitates is larger than those of precipitates grown at lower temperatures, but the density is significantly lower than those at lower temperatures.

Table 1 summarizes the measured size and density of needle-shape precipitates of specimens heated to each temperature. It can be noticed that the density of precipitates increases when temperature rises from 623 $\mathrm{K}$ to $773 \mathrm{~K}$ and their size increases, nearly doubles. In the temperature-range $623 \mathrm{~K}$ to $773 \mathrm{~K}$, their density still increases, but their sizes did not change so much. However, at $923 \mathrm{~K}$, a significant decrease in precipitation density occurred while precipitations' size significantly increased. Figure 5 indicates the variations of density (^) of needle-shaped precipitates and hardness increasing-rates $(\Delta \mathrm{Hv})$ with temperature-rising. $\Delta \mathrm{Hv}$ corresponds to the difference in hardness value between the heated specimen and the solution-treated state. As temperature rises from $623 \mathrm{~K}$ to $773 \mathrm{~K}, \Delta \mathrm{Hv}$ increased, while the rate at $923 \mathrm{~K}$ decreased.

Figs. 4 and 5 reveal the variations of density ( $\wedge$ ) and $\Delta H v$-depending on temperatures. Both indicate the same trend. Shear stress of age-hardened materials is decided by mean distances between precipitates, their sizes and strength. Their distance depends on $\curlywedge-1 / 2$. It is also known that there are two hardeningmechanism: 1) shearing-mechanism and 2) by-pass one, and they are concerned with size and density of precipitates. Therefore, the results revealed in Figs. 4 and 5 predict that hardening-mechanism at $623 \mathrm{~K}, 693$ $\mathrm{K}$ and $773 \mathrm{~K}$ is shear-mechanism, and the mechanism at $923 \mathrm{~K}$ is by-pass one. In order to confirm these predictions, it seems to be necessary to observe interaction between dislocation and precipitates.

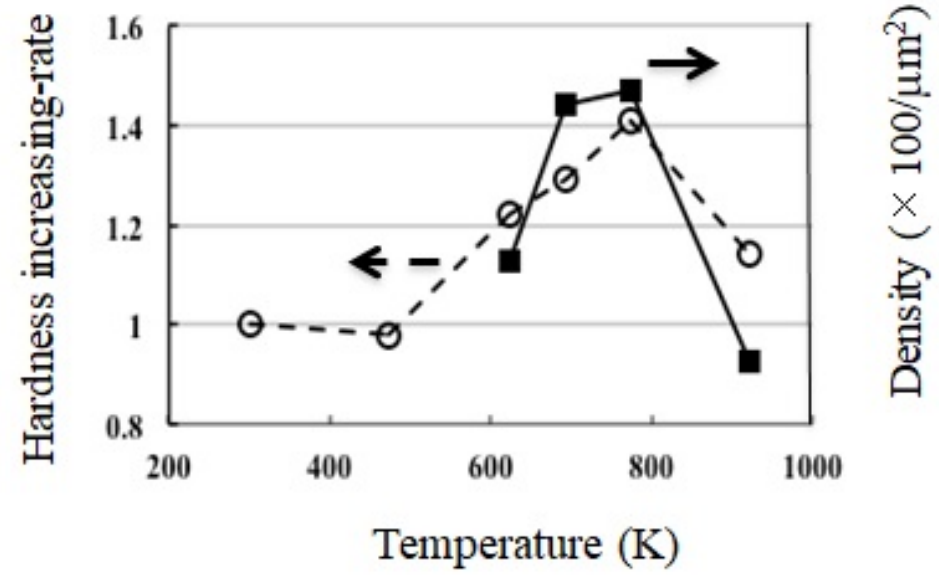

Figure 5: $\Delta \mathrm{Hv}$ increasing rate and density of needle-shaped precipitates heated at each temperature. Density of precipitates indicates $\times 100$ particles $/ \mathrm{mm}^{2}$ of specimens heated at $623 \mathrm{~K}$ to $923 \mathrm{~K}$.

From electron diffraction patterns, it is possible to conclude that in the as quenched condition we have a mixture of $\beta$ phase with very small athermal $\omega$ precipitates. After heating at $473 \mathrm{~K}$, the microstructure did not change significantly. Reaching $623 \mathrm{~K}$, $\omega$ precipitates are clearly observed as well as $\alpha$ or $\alpha$ "iso. At the higher temperature only $\beta$ and $\alpha$ phase remain.

It can be mentioned that neither athermal $\omega$ nor $\alpha$ " iso were identified by HEXRD at respectively room temperature or $623 \mathrm{~K}$ (Figure 1). TEM results evidence that for both cases, the size and amount of precipitates are very small. We can thus consider that HEXRD peaks corresponding to $\alpha$ "iso are enlarged and in the background of the diffraction response. Moreover, the precipitation of $\alpha$ "iso in a Ti-5553 specimen isothermally transformed at 598K was characterized by HEXRD for holding times larger than $110 \mathrm{~min}$ [16].

On Fig. 2(b), the distinction between $\alpha$ "iso and $\alpha$ was mentioned. Figure 6 shows dark field images of specimens heated to $623 \mathrm{~K}$ in (a) and $773 \mathrm{~K}$ in (b). Figure 6(a) was taken using $\omega$ and $\alpha$ "iso (or $\alpha$ )-spots. 
Needle-like precipitates are $\alpha$ "iso (or $\alpha$ )-ones, and small round-like precipitates seem to be $\omega$-ones. Fig. 6(b) was taken using $\alpha$ "-spots. White arrows in the both images indicate two $<112>$ directions of the matrix. Each direction of needle-like precipitates is not parallel to $<112>$ directions. By the way, it is found that growthdirections of grain-boundary $\alpha$-precipitates in a Ti-15-3 alloy aged at $873 \mathrm{~K}$ for $11 \mathrm{ks}$ were parallel to $<112>$ directions of the matrix [17]. However, it is reported that growth-directions of aged $\alpha$-precipitates in some $\beta$ Ti alloys are not parallel to $<112>$ directions $[17,18]$, and it is also found that in the case of $\alpha$-precipitates satisfied with Burger's orientation relationship, <21-30>-directions of $\alpha$-precipitates are shifted by approximately 5 degree from $\langle 110\rangle$ direction of the matrix [18]. It is predicted that investigation about the angle between two growth-directions of $\alpha$-precipitates might be given some information about $\alpha$ "iso - and $\alpha$ phases.
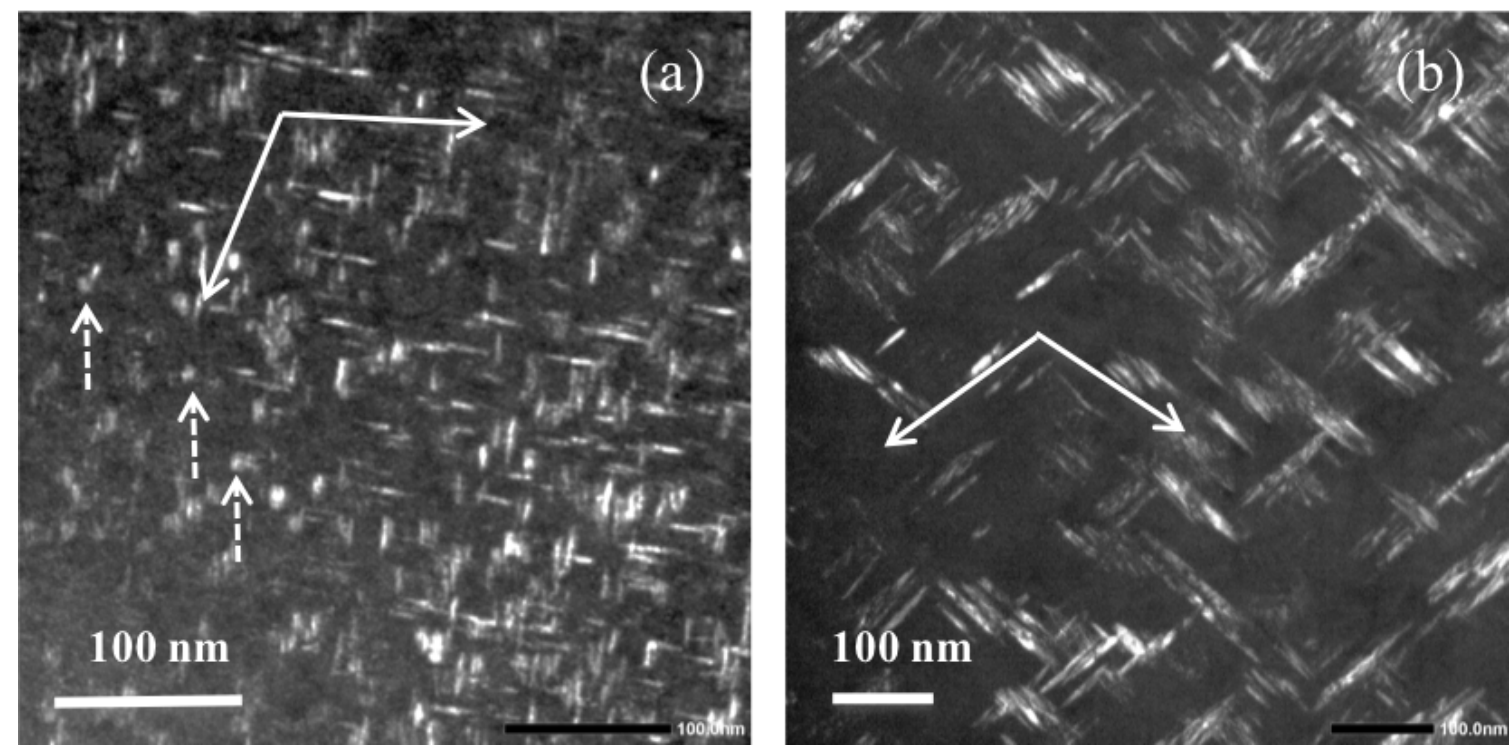

Figure 6: Dark field images of specimens heated to $623 \mathrm{~K}$ (a) and $773 \mathrm{~K}(\mathrm{~b})$. White arrows indicate directions of $<112>\beta$. White dotted-arrows indicate small round-like precipitates. Scale-bars indicate $100 \mathrm{~nm}$.
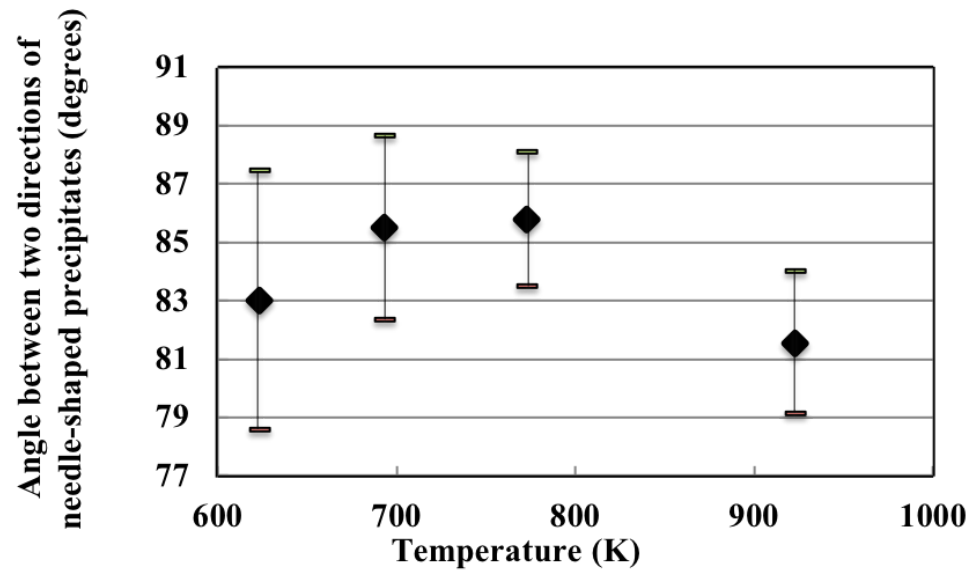

Figure 7: Angle between two directions of needle-shaped precipitates in the specimens heated to each temperature

Figure 7 shows distributions of angles between two growth-directions of needle-like precipitates in the specimens heated to each temperature. If they are parallel to the two $<112>$ directions of the matrix, the angle is 72 degrees. Only angles at $693 \mathrm{~K}, 773 \mathrm{~K}$ and $923 \mathrm{~K}$ are considered, because it is predicted that needle-like precipitates at $623 \mathrm{~K}$ did not grow enough. So, Fig. 7 indicates that the angles at $693 \mathrm{~K}$ and 773 $\mathrm{K}$ are larger than that at $923 \mathrm{~K}$. This result suggests that it seems to be possible to distinguish $\alpha$ " iso and $\alpha$ by comparing with angles between two growth-directions of needle-like precipitates; 86 degree for $\alpha$ " iso-phase and 82 degree for $\alpha$-phase. 


\section{$\underline{\text { Summary }}$}

Ti-5553 alloy specimens were continuously heated to $923 \mathrm{~K}$ at $0.1 \mathrm{~K} / \mathrm{s}$ and in-situ HEXRD profiles were taken. TEM observations of specimens heated at $0.1 \mathrm{~K} / \mathrm{sec}$ to $473 \mathrm{~K}, 623 \mathrm{~K}, 693 \mathrm{~K}, 773 \mathrm{~K}$ and $923 \mathrm{~K}$ were carried out. Based on results taken by two methods, transformation sequence, size and density of precipitates due to continuous-heating were investigated. Hardness values of specimens solution-treated and heated to each temperature were also measured, and hardening mechanism was discussed. The results obtained are as follows:

1. $\omega$-phase precipitates were observed at $473 \mathrm{~K}, 623 \mathrm{~K}, \alpha$ " iso-phase precipitates were observed at $623 \mathrm{~K}$, $693 \mathrm{~K}$, and $773 \mathrm{~K}$, and $\alpha$-phase precipitates were observed at $923 \mathrm{~K}$.

2. It is found that trends of increase and decrease about density of precipitates and hardness values are the same. The result suggests that hardening mechanisms due to precipitates in this alloy are shearingmechanism in the specimens heated $693 \mathrm{~K}$ and $773 \mathrm{~K}$ and by-pas one at $923 \mathrm{~K}$.

3. It is considered that distinction between $\alpha$ "iso-precipitates and $\alpha$-precipitates is possible by comparing the angles between 2 directions of needle-like precipitates.

\section{$\underline{\text { References }}$}

[1] G. M. Pennock, H. M. Flower and D. R. F. West: Titanium '80 Science and Technology, ed. by H. Kimura and O. Izumi, (Japan Inst. Metals, 1980) pp. 1343-1351.

[2] M. Okada, D. Banerjee and J. C. Williams: Titanium Science and Technology, ed. by G. Lutjering, U. Zwicker and W. Bunk (D. G. M., 1985) pp. 1835-1842.

[3] C. Ouchi, H. Suenaga and Y. Kohsaka: Sixth World Conference on Titanium, Proc., ed. by P. Lacombe,

R. Tricot and G. Beranger (Societe Francaise de Metallurgie, 1988) pp. 819-824.

[4] A. Settefrati, M. Dehmas, G. Geandier, B. Denand, E. Aeby-Gautier, B. Appolaire, G. Khelifati, J.

Delfosse : Proceedings of Ti-2011, Beijing, China, 1, (2011) 468-472.

[5] P. Barriobero-Vila, G. Requena, S. Schwarz, F. Warchomicka, T. Buslaps: Acta Mater. 95, (2015) 90-101.

[6] F. Bruneseaux, G. Geandier, E. Gautier, M. Dehmas, P. Boulet: Proceedings of the 11th World

Conference on Titanium, 5, (2007) 563-566.

[7] P. Barriobero-Vila, G. Requena, F. Warchomicka, A. Stark, N. Schell, T. Buslaps:

J. Mater. Sci. 50 (3), (2015) 1412-1426.

[8] R. Sanguinetti, M. Zandona, A. Pianelli, E. Gautier: J. Phys. IV 3 (C7), (1993) 527-531.

[9] M. J. Blackburn, J. C. Williams: Trans. Met. Soc. AIME. 242, (1968) 2461-2469.

[10] F. Prima, P. Vermaut, G. Texier, D. Ansel, T. Gloriant: Scripta Materialia 54 (2006) 645-648.

[11] S. Nag, R. Banerjee, R. Srinivasan, J.Y. Hwang, M. Harper, H.L. Fraser: Acta Mater. 57 (7), (2009) 2136-2147.

[12] N.G. Jones, R.J. Dashwood, M. Jackson, D. Dye: Acta Mater. 57 (13), (2009) 3830-3839.

[13] Y. Zheng, R. E.A. Williams, H. L. Fraser: Scripta Materialia 113 (2016), 202-205.

[14] E. Sukedai, H. Hashimoto, M. Hida, H. Mabuchi; Mater. Sci. and Tech., 8 (1992) 3-9.

[15] E. Sukedai, H. Yagi, D. Yoshimitsu, H. Matsumoto, T. Ando, W. F. Wei, H. Hashimoto:

Ultramicroscopy 98 (2004) 209-218.

[16] E. Aeby-Gautier A. Settefrati, F. Bruneseaux, B. Appolaire, B. Denand, M. Dehmas, G. Geandier, P. Boulet: Journal of Alloys and Compounds, vol 577, Supplement 1, (2012) S439-S443.

[17] E Sukedai, T. Hashiguchi, M. Naruse, E. Tanabe; to be submitted Trans JIM (2019)

[18] Y. Takemoto, M. Hida, A. Sakakibara: J. Japan Inst. Metals, 57 (1993) 261-267.

\section{Acknowledgement}

We would like to sincerely thank to Messrs. S. Yamashita and K. Suemune of undergraduate students of Okayama University of Science for collaborating specimen-preparations, and a professor emeritus M. Tanaka of Tohoku University and Mr. K. Fukunaga of EM Application Department of JEOL for collaborating observation of Fig. 6. 